\title{
Predicting Telemedicine Adoption: An Empirical Study on the Moderating Effect of Plasticity in Brazilian Patients
}

\author{
Catalina Ramírez-Rivas ${ }^{1}$, Jorge Alfaro-Pérez ${ }^{1}$, Patricio Ramírez-Correa ${ }^{{ }^{\star}}$, Ari Mariano-Melo ${ }^{2}$
}

\author{
${ }^{1}$ Universidad Católica del Norte, Coquimbo, CHILE \\ ${ }^{2}$ Universidade de Brasília, Brasília, BRAZIL \\ *Corresponding Author: patricio.ramirez@ucn.cl
}

Citation: Ramírez-Rivas, C., Alfaro-Pérez, J., Ramírez-Correa, P. and Mariano-Melo, A. (2021). Predicting Telemedicine Adoption: An Empirical Study on the Moderating Effect of Plasticity in Brazilian Patients. Journal of Information Systems Engineering and Management, 6(1), em0135. https://doi.org/10.29333/jisem/9618

\begin{tabular}{|c|c|}
\hline ARTICLE INFO & ABSTRACT \\
\hline Published: 20 Jan. 2021 & $\begin{array}{l}\text { Predicting behaviors around telemedicine acceptance in developing countries is an important developing area of } \\
\text { study. This importance has been enhanced since the emergence of the COVID- } 19 \text { pandemic, especially in Latin } \\
\text { America. In this context, this study aims to explore the effect of plasticity on telemedicine acceptance in Brazil. } \\
\text { This paper focuses on Brazilian patients and their acceptance of telemedicine through the Theory of Planned } \\
\text { Behavior and the concept of Plasticity as a superordinate factor of the patients' personality traits. An online survey } \\
\text { of Brazilian patients was carried out, and structural model modeling was then utilized. Results indicate that the } \\
\text { proposed model explains } 62.1 \% \text { of the behavioral intention of the use of telemedicine by the patients. } \\
\text { Furthermore, the findings suggest that attitude has the most substantial direct effect on behavioral intention, with } \\
\text { plasticity playing a considerable role in the strength of the impact. Government strategies for the spread of } \\
\text { telemedicine in Latin America could consider these results for their design. }\end{array}$ \\
\hline
\end{tabular}

Keywords: telemedicine, Brazil, plasticity, theory of planned behavior, SEM

\section{INTRODUCTION}

Now more than ever, health services in developing countries must provide high-quality services to achieve their success in a scenario of high demand and significant budget constraints (Meesala and Paul, 2018). Although there are several options for providing these health services, the evaluation of their success implies, among other things, determining the perception that patients have regarding these alternatives. Over the last decade, there has been a rise in mobile phone usage and access to highspeed mobile networks. This technology shift has created a rise in mobile-related offerings, from food delivery services to mobile health services (Dick et al., 2020), also known as telemedicine, which is the focus of this paper.

In this context, explaining behaviors around telemedicine acceptance in developing countries is an important developing area of study, and this importance has been enhanced since the emergence of the COVID-19 pandemic, especially in Latin America. This paper looks at the acceptance of telemedicine in a Brazilian setting. As of mid-2019, the Brazilian National Medicine Council (Conselho Federal de Medicina - CFM) has allowed the use of telemedicine to conduct consultations over the internet. While informal telemedicine services have been available previously for patients through instant messaging applications, the acceptance of this method by the CFM brings detailed regulations that practitioners and businesses offering telemedicine solutions need to follow. The CFM defines telemedicine as "the exercise of medicine mediated by technologies for the purposes of assistance, education, research, disease and injury prevention, and health promotion." (CFM, 2019). The introduction of telemedicine as an option for Brazilian patients aims to allow patients from the more remote areas of Brazil to have access to quality health services, as well as to allow for faster access to medical assistance, as telemedicine aims to reduce the load on demand for in-person consultations. In terms of the COVID-19 pandemic, this would minimize exposure of patients (Portnoy, Waller, and Elliott, 2020) and increase the amount of available medical resources as quarantined staff could still carry-out telemedicine consultations (Adams and Walls, 2020; Hollander and Carr, 2020).

Overall, this study aims to explore the effect of plasticity on telemedicine acceptance in Brazil. Based on this shift towards telemedicine, this paper focuses on the acceptance of telemedicine in a Brazilian context, and how using the Theory of Planned Behavior (TPB) (Ajzen, 1991) and the idea of plasticity, we can explain an individual's intention to use the telemedicine services available to them. TPB is a widely recognized physiological theory of human behavior, and plasticity is a superordinate factor regarding personal traits. An essential contribution of this paper is to understand which of the constructs we are measuring provide a more significant explanation of the usage of telemedicine, and therefore should be the best point to focus on when trying 
to increase the patients' participation in telemedicine. This article extends the preliminary results previously delivered in (Ramirez-Rivas et al., 2020).

This paper consists of five sections. The second section looks at the existing literature surrounding telemedicine and its acceptance. This section also lays the groundwork for the theories that form the proposed model presented in this study. The third part is the methodology of the study and explains the data collection process as well as the methods that were used to analyze the data. The results of this data analysis are presented in the fourth section of this study and then summed up in conclusion.

\section{LITERATURE REVIEW AND HYPOTHESES}

The concept of telemedicine has many names across literature, but the core of the concept is the use of big data and cloud computing as well as high-speed connectivity to monitor and aid people with their health queries. Intention to use these services is also an existing topic within the literature. Lin \& Yang (Lin and Yang, 2009) observed the intention to use telemedicine in an offering called Asthma Care Mobile Service (ACMS), which monitors the real-time conditions of asthma patients. In this preventative use of telemedicine, ACMS alerted participating individuals of any environmental changes that might deteriorate or affect their condition before this occurred. In the study, the authors considered the Technology Acceptance Model (TAM) model, along with the concept of subjective norm and innovativeness, in order to predict behavioral intention to use. The outcomes of the study pointed to attitude as being the most critical factor affecting behavioral intention to use ACMS. Other papers have found similar results, in which attitude is a significant predictor for behavioral intention (Harst, Lantzsch, and Scheibe, 2019; Jen and Hung, 2010; Lin and Yang, 2009).

Another use of telemedicine found in the literature is a more reactive use (Zhao, Ni, and Zhou, 2018), such as the one that the system looked at in this paper. A reactive telemedicine system is one where an individual can contact a doctor through their mobile rather than having to attend an in-person consultation (Zhang et al., 2017). This would reduce the time it would take to obtain a diagnosis, and be a safer alternative for people who are in limited conditions to leave their residence or have limited mobility. For these reactive uses of telemedicine, the results found in literature also point towards attitude being the predicting factor of behavioral intention (Huygens et al., 2015).

For this paper, following past research around behavioral intention (BI) to use telemedicine services, the TPB was used to explain BI. TPB has been previously used in literature within a Latin American context to successfully explain different usage behaviors. Some of these uses of TPB have been within the areas of education (Painén-Aravena et al., 2019), e-commerce (Grandón and Ramírez-Correa, 2018), and public health (Ramírez-Correa and Ramírez-Santana, 2018).

TPB was developed from the Theory of Reasoned Action (TRA) (Fishbein and Ajzen, 1975). TRA proposes that attitude (ATT) towards a behavior and subjective norms (SN) around that behavior (such as perceptions of those surrounding an individual regarding the behavior) have a direct effect on the individual's behavioral intention. This intention is their intent to partake in the behavior. TPB adds another concept that explains behavioral intention, which is perceived behavioral control (PBC). PBC refers to an individual's perceived ability to perform that behavior. Based on these three key concepts of TPB, the first three hypotheses were developed.

Attitude refers to how an individual perceives a behavior. If the individual perceives the behavior as beneficial to himself or herself, then they are more likely to participate in the behavior, this leads to our first proposed hypothesis:

\section{H1: Attitude has a positive effect on behavioral intention of the use of telemedicine by the Brazilian patient.}

Social norms relate to how the individual perceives other's beliefs in regard to engaging in the behavior. If the individual perceives participating in the behavior as viewed positively by those around him or her, then they are more likely to participate in the behavior. From this, we get our second proposed hypothesis:

\section{H2: Social norms have a positive effect on behavioral intention of the use of telemedicine by the Brazilian patient.}

Perceived behavioral control looks at if the individual believes that carrying out behavior is within their capabilities. If the individuals perceive that participation in the behavior is within their capabilities to perform, they will likely have a high intention to carry out the behavior. This idea leads to our third proposed hypothesis:

H3: Perceived behavioral control has a positive effect on behavioral intention of the use of telemedicine by the Brazilian patient.

Another effect measured in this study is the role of plasticity $(P)$ in affecting behavioral intention. Based on the idea of the big five personality traits (emotional stability, agreeableness, conscientiousness, extraversion, and openness), DeYoung et al. (Deyoung, Peterson, and Higgins, no date) looked at how to predict conformity by measuring stability and plasticity. From the five traits, stability relates to emotional stability, agreeableness, and conscientiousness, on the other hand, plasticity relates to extraversion and openness. By splitting the big five into the concepts of stability and plasticity, it was found that plasticity negatively predicts conformity. The higher an individual scores in the extraversion and openness traits, the higher their plasticity score, which in turn indicates a lower level of conformity.

Based on the idea that higher plasticity means more openness to participate in new behaviors, this research examines the relation of plasticity in predicting the behavioral intention to use a telemedicine system within a Brazilian context. Then, we proposed the last hypothesis:

H4: Plasticity acts as a moderator in the explanation of the behavioral intention of the use of telemedicine by the Brazilian patient. 


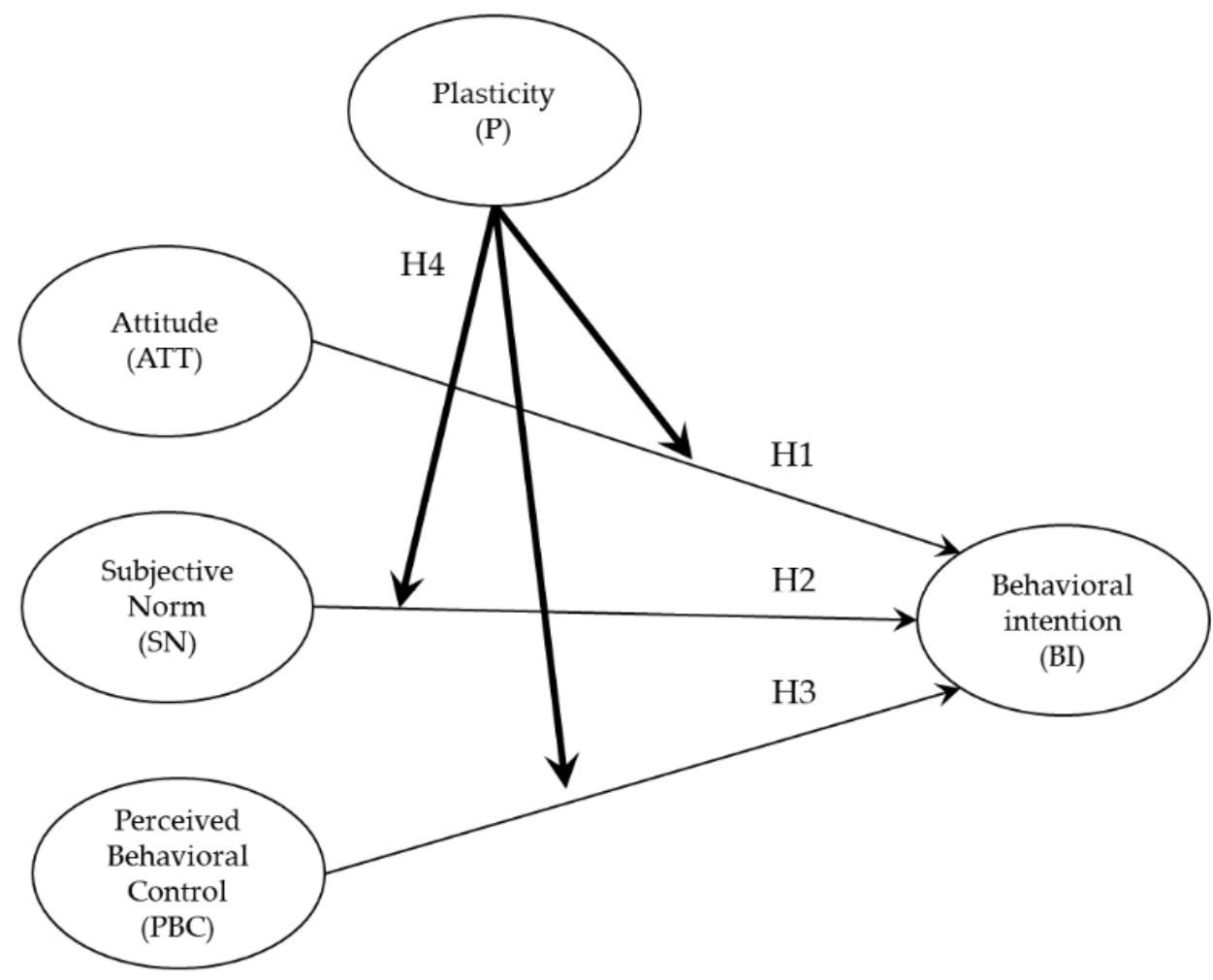

\section{$\longrightarrow$ Direct effect $\longrightarrow$ Relationship moderation}

Figure 1. Proposed model and hypotheses

Figure 1 presents the research model with the four hypotheses.

\section{METHODOLOGY}

In order to carry out the study and measure the validity of the proposed model, an online survey was carried out within a Brazilian population regarding their intention to utilize telemedicine services.

The measurement scales were adapted from the literature. A seven-point Likert scale was used in order to measure all items besides the demographic data. In the instrument, there were four items measuring attitude, and three items each to measure subjective norms, perceived behavioral control, and behavioral intention.

Survey data was collected in December 2019 via online means, and a total of 100 valid responses were obtained. Prospective telemedicine users were contacted for their participation from two groups. Tertiary students from Brasilia were first contacted, followed by contacting social network users throughout Brazil. The overall answer ratio was $14.57 \%$. Of the respondents, the mean age was 32 (SD 14.4), with a range from 18 (minimum permitted age to participate) to 72 years old. $66 \%$ of the respondents were of the male gender. Respondents showed a mean mobile phone experience of 14.8 years with a standard deviation of 6.8 .

The research model was analyzed using Partial Least Squares structural equation modeling (PLS) on the SmartPLS 3 software. From the collected data, a PLS analysis was carried out on all the data collected in order to validate the proposed model. This was followed by a secondary analysis where the data was separated into two groups, high and low plasticity.

As part of the instrument, a ten-item personality measure (TIPI) was used (Gosling, Rentfrow, and Swann, 2003). The measurement scale was followed, and two groups were created from the data. Respondents with medium-high or high scores in both openness and extraversion were assigned to the high plasticity group $(n=42)$ while respondents with medium-low or low scores in either item were placed in the low plasticity group $(n=58)$. Following this data split, a PLS analysis was carried out on each group individually. In order to compare both groups through a multi-group analysis (MGA) (Sarstedt, Henseler, and Ringle, 2011), a measurement invariance assessment (MICOM) (Henseler, Ringle and Sarstedt, 2016) was first carried out. After a successful MICOM, the MGA analysis was carried out on the groups. 


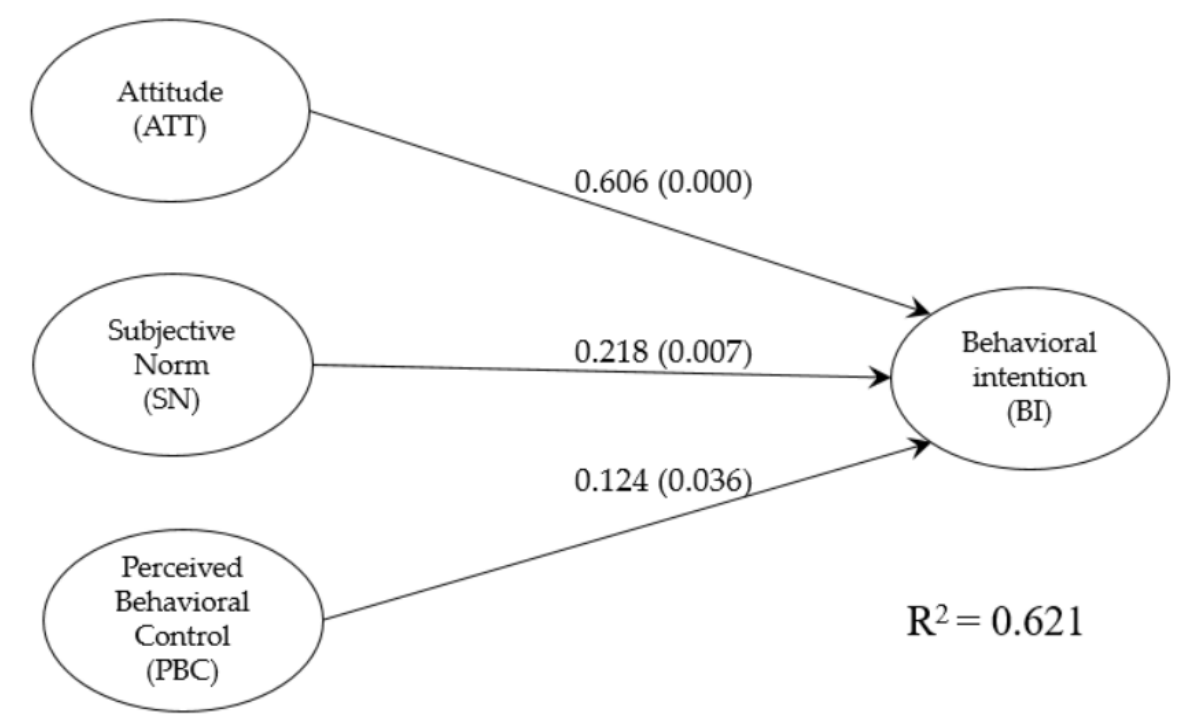

Figure 2. Results from PLS analysis of all collected data

Table 1. PLS Structural results

\begin{tabular}{|c|c|c|c|c|c|c|}
\hline \multirow{2}{*}{ Relationships } & \multicolumn{2}{|c|}{ All } & \multicolumn{2}{|c|}{ Low $P$} & \multicolumn{2}{|c|}{ High $\mathbf{P}$} \\
\hline & Beta & p-value & Beta & p-value & Beta & p-value \\
\hline ATT $->$ BI & 0.606 & 0.000 & 0.454 & 0.000 & 0.760 & 0.000 \\
\hline PBC $->\mathrm{BI}$ & 0.124 & 0.036 & 0.152 & 0.079 & 0.096 & 0.323 \\
\hline $\mathrm{SN}->\mathrm{BI}$ & 0.218 & 0.007 & 0.357 & 0.002 & 0.086 & 0.476 \\
\hline
\end{tabular}

Table 2. PLS-MGA results

\begin{tabular}{cccc}
\hline Relationships & $\begin{array}{c}\text { Path Coefficients Differences } \\
\text { (|Low P- High P|) }\end{array}$ & \multicolumn{2}{c}{ P-value } \\
\cline { 2 - 4 } & 0.306 & 0.980 & Welch-Satterthwait Test \\
\hline ATT - B & 0.056 & 0.318 & 0.049 \\
\hline PBC - BI & 0.271 & 0.056 & 0.663 \\
\hline
\end{tabular}

\section{RESULTS}

The initial PLS analysis of all the data reported a coefficient of determination $\left(R^{2}\right)$ of 0.621 . This allows us to interpret that the independent variables in the model (ATT, SN, and PBC) explain $62.1 \%$ of the variance of the behavioral intention to use telemedicine.

The findings in regard to the path coefficients were aligned to the literature, with ATT, SN, and PBC all having positive effects on $\mathrm{BI}(\beta=0.606, p=0.000, \beta=0.124, p=0.036$, and $\beta=0.218, p=0.007)$. This means that an increase in the value of these independent variables causes an increase in the value of behavioral intention. These findings support $\mathrm{H} 1, \mathrm{H} 2$, and $\mathrm{H} 3$. These outcomes can be seen in Figure 2.

The second part of the results, where the moderating effect of plasticity is analyzed, showed that for the high plasticity group, the model had an $\mathrm{R}^{2}$ value of 0.716 . In contrast, the low plasticity group had an $\mathrm{R}^{2}$ value of 0.583 . For both groups, ATT remained as having a significant positive effect on $\mathrm{Bl}$, as observed in Table 1.

The results from the MGA showed that plasticity is a significant moderator in the relationship between ATT and BI, as shown by the results in Table 2. These results indicate only partial support for $\mathrm{H} 4$ as Plasticity did not prove to be a moderator for SN or PCB.

\section{CONCLUSIONS}

This study examines which variables from the TPB played a more critical role in explaining the behavioral intention to use telemedicine solutions from a Brazilian patient's perspective. The findings are in line with previous studies in the field, which point to attitude being the critical factor when it comes to explaining behavioral intention. This study also looked at the mediating effect of plasticity on the TPB and found that plasticity had a mediating effect on attitude. As plasticity is a personality meta-trait indicating openness and extroversion, this would suggest that more open and extroverted people tend to have a more positive attitude when it comes to their intention to participate in the behavior. For the context of this study, this would mean that patients 
who are more introverted and unwilling to try new things might have lower attitude scores and therefore be less likely to use telemedicine and stick to the old ways of obtaining healthcare.

Since attitude proved to be the most shaping factor in a patient's intention to use telemedicine services, providers of these services could focus on shaping patient's attitudes towards these systems in order to get more people using telemedicine services. While currently there is not a big uptake in this technology (Ipsos Global, 2018), the shift to telemedicine over in-person healthcare will prove to be an essential item in providing quality healthcare in developing countries, as it brings an effective solution to patients who would otherwise have difficulties getting medical attention due to mobility or distance issues. This is especially true in the context of limiting travel during the COVID-19 pandemic (Oliveira et al., 2020). Government strategies for the spread of telemedicine in Latin America could consider these results for their design.

The main limitations of this study include the small sample size of the survey and the results being from a non-probability sample, as it was limited to those with access to the survey and not an accurate representation of all possible telemedicine patients in Brazil. Another limitation lies in the high age heterogeneity of respondents.

Future research should focus on a larger sample size, which is more representative of the population of Brazil, and measure if the proposed model shows validity in this larger setting. Also, to further understand causes relating to the acceptance of telemedicine, futures studies could do a qualitative evaluation of this behavior. Another future point of research is around plasticity concerning its role in different information technology acceptance behaviors. Investigating the role of plasticity might highlight how existing personality traits can aid in explaining the acceptance and usage intention of information technology systems. Specifically, it would be advantageous to research the role of plasticity concerning the usage intention and acceptance of different health-related information technology systems. These systems might include reactive systems like telesurgery, firstaid/emergency services, or proactive systems such as heart-rate monitoring, pill-taking reminders, and other monitoring systems. This same approach can be taken with previously implemented telemedicine solutions in Brazil, such as that used for the Zika virus (Ohannessian, Duong, and Odone, 2020). Such research would allow telemedicine providers to closely pinpoint what the right strategy is to generate an update in this technology within the Brazilian population.

\section{REFERENCES}

Adams, J. G. and Walls, R. M. (2020). Supporting the Health Care Workforce during the COVID-19 Global Epidemic. JAMA, 323(15), 1439-1440. https://doi.org/10.1001/jama.2020.3972

Ajzen, I. (1991). The theory of planned behavior. Organizational Behavior and Human Decision Processes, 50(2), $179-211$. https://doi.org/10.1016/0749-5978(91)90020-T

CFM. (2019) Telemedicina: CFM regulamenta atendimentos online no Brasil. Available at: http://www.portal.cfm.org.br/index.php?option=com_content\&view=article\&id=28061

Deyoung, C. G., Peterson, J. B. and Higgins, D. M. (2002). Higher-order factors of the Big Five predict conformity: Are there neuroses of health? Personality and Individual Differences, 33(4), 533-552. https://doi.org/10.1016/S0191-8869(01)00171-4

Dick, S., O'Connor, Y., Thompson, M. J., O’Donoghue, J., et al. (2020). Considerations for Improved Mobile Health Evaluation: Retrospective Qualitative Investigation. JMIR mHealth and uHealth, 8(1), e12424. https://doi.org/10.2196/12424

Fishbein, M. and Ajzen, I. (1975). Belief, attitude, intention and behaviour: An introduction to theory and research. Reading, MA: Addison-Wesley.

Gosling, S. D., Rentfrow, P. J. and Swann, W. B. (2003). A very brief measure of the Big-Five personality domains. Journal of Research in Personality, 37(6), 504-528. https://doi.org/10.1016/S0092-6566(03)00046-1

Grandón, E. E. and Ramírez-Correa, P. (2018). Managers/owners' innovativeness and electronic commerce acceptance in chilean smes: A multi-group analysis based on a structural equation model. Journal of Theoretical and Applied Electronic Commerce Research, 13(3), 1-16. https://doi.org/10.4067/S0718-18762018000300102

Harst, L., Lantzsch, H. and Scheibe, M. (2019). Theories predicting end-user acceptance of telemedicine use: Systematic review. Journal of Medical Internet Research, 21(5), e13117. https://doi.org/10.2196/13117

Henseler, J., Ringle, C. M. and Sarstedt, M. (2016). Testing measurement invariance of composites using partial least squares. International Marketing Review, 33(3), 405-431. https://doi.org/10.1108/IMR-09-2014-0304

Hollander, J. E. and Carr, B. G. (2020). Virtually Perfect? Telemedicine for Covid-19. New England Journal of Medicine, 382(18), 16791681. https://doi.org/10.1056/NEJMp2003539

Huygens, M. W., Vermeulen, J., Friele, R. D., van Schayck, O. C. P., et al. (2015). Internet Services for Communicating with the General Practice: Barely Noticed and Used by Patients. Interactive Journal of Medical Research, 4(4), e21. https://doi.org/10.2196/ijmr.4245

Ipsos Global. (2018). Global Views on Healthcare Summary of Findings Personal Health Perceptions.

Jen, W.-Y. and Hung, M.-C. (2010). An Empirical Study of Adopting Mobile Healthcare Service: The Family's Perspective on the Healthcare Needs of Their Elderly Members. Telemedicine and e-Health, 16(1), 41-48. https://doi.org/10.1089/tmj.2009.0093

Lin, S. P. and Yang, H. Y. (2009). Exploring key factors in the choice of e-health using an asthma care mobile service model. Telemedicine and e-Health, 15(9), 884-890. https://doi.org/10.1089/tmj.2009.0047 
Meesala, A. and Paul, J. (2018). Service quality, consumer satisfaction and loyalty in hospitals: Thinking for the future. Journal of Retailing and Consumer Services, 40, 261-269. https://doi.org/https://doi.org/10.1016/j.jretconser.2016.10.011

Ohannessian, R., Duong, T. A. and Odone, A. (2020). Global Telemedicine Implementation and Integration Within Health Systems to Fight the COVID-19 Pandemic: A Call to Action. JMIR Public Health and Surveillance, 6(2), e18810. https://doi.org/10.2196/18810

Oliveira, W. K. de, Duarte, E., França, G. V. A. de, Garcia, L. P. (2020). How Brazil can hold back CoVID-19. Epidemiologia e servicos de saude: revista do Sistema Unico de Saude do Brasil, 29(2), e2020044. https://doi.org/10.5123/s1679-49742020000200023

Painén-Aravena, G., Alfaro-Pérez, J., Ramírez-Correa, P., Grandón, E. E. and Araya-Guzmán, S. (2019). Investigating the effect of learning styles on the acceptance of e-books among university students. In Iberian Conference on Information Systems and Technologies, CISTI. IEEE Computer Society. https://doi.org/10.23919/CISTI.2019.8760702

Portnoy, J., Waller, M. and Elliott, T. (2020). Telemedicine in the Era of COVID-19. Journal of Allergy and Clinical Immunology: In Practice, 8(5), 1489-1491. https://doi.org/10.1016/j.jaip.2020.03.008

Ramírez-Correa, P. and Ramírez-Santana, M. (2018). Predicting Condom Use among Undergraduate Students Based on the Theory of Planned Behaviour, Coquimbo, Chile, 2016. International Journal of Environmental Research and Public Health, $15(8), 1689$. https://doi.org/10.3390/ijerph15081689

Ramírez-Rivas, C., Alfaro-Pérez, J., Ramírez-Correa, P. and Mariano-Melo, A. (2020). Telemedicine Acceptance in Brazil: Explaining behavioral intention to move towards internet-based medical consultations. In 2020 15th Iberian Conference on Information Systems and Technologies (CISTI). IEEE, pp. 1-4. https://doi.org/10.23919/CISTI49556.2020.9140996

Sarstedt, M., Henseler, J. and Ringle, C. M. (2011). Multigroup analysis in partial least squares (PLS) path modeling: Alternative methods and empirical results. Advances in International Marketing, 22, 195-218. https://doi.org/10.1108/S14747979(2011)0000022012

Zhang, X., Han, X., Dang, Y., Meng, F., Guo, X. and Lin, J. (2017). User acceptance of mobile health services from users' perspectives: The role of self-efficacy and response-efficacy in technology acceptance. Informatics for Health and Social Care, 42(2), $194-206$. https://doi.org/10.1080/17538157.2016.1200053

Zhao, Y., Ni, Q. and Zhou, R. (2018). What factors influence the mobile health service adoption? A meta-analysis and the moderating role of age. International Journal of Information Management, 342-350. https://doi.org/10.1016/j.ijinfomgt.2017.08.006 